Original Research Article

\title{
Effect of vitamin D on vascular health in hypertensive patients with vitamin D deficiency
}

\author{
Suresh Kumar Srinivasamurthy ${ }^{1}$, Sadish Kumar Kamalanathan ${ }^{2}$, Vishwanath Vinod Kolar ${ }^{3}$, \\ Rajan Sundaram ${ }^{4}$, Charan Raj Goud ${ }^{4}$, Adithan Chandrasekaran ${ }^{1}$
}

\begin{abstract}
${ }^{1}$ Department of Clinical
Pharmacology, Jawaharlal

Institute of Postgraduate

Medical Education and

Research, Puducherry 6, India

${ }^{2}$ Department of Endocrinology,

Jawaharlal Institute of

Postgraduate Medical Education and Research, Puducherry 6, India

${ }^{3}$ Department of Medicine,

Jawaharlal Institute of

Postgraduate Medical Education and Research, Puducherry 6, India

${ }^{4}$ Department of Pharmacology, Jawaharlal Institute of Postgraduate Medical Education and Research, Puducherry 6, India
\end{abstract}

Received: 21 September 2016 Accepted: 26 October 2016

*Correspondence to:

Dr. Suresh Kumar

Srinivasamurthy,

Email: sureskums@gmail.com

Copyright: (c) the author(s), publisher and licensee Medip Academy. This is an openaccess article distributed under the terms of the Creative Commons Attribution NonCommercial License, which permits unrestricted noncommercial use, distribution, and reproduction in any medium, provided the original work is properly cited.

\begin{abstract}
Background: Many observational studies have shown association of cardiovascular disease and vitamin D deficiency. However, there is a need for prospective studies to show causal effect of vitamin D and cardiovascular diseases in India. Hence the present study was designed to study the effect of vitamin $\mathrm{D}$ on markers of vascular health in hypertensive patients with vitamin $\mathrm{D}$ deficiency. The objective of the study was to assess the effect of vitamin D supplementation on markers of vascular health in hypertensive patients with vitamin D deficiency.

Methods: Hypertensive patients were screened for vitamin D deficiency defined as $25 \mathrm{OH}$ vitamin D less than $20 \mathrm{ng} / \mathrm{mL}$ after written informed consent. Hypertensives deficient with $25 \mathrm{OH}$ vitamin D were recruited for the study to receive cholecalciferol $60000 \mathrm{IU} /$ week for 8 weeks. The vascular parameters such as blood pressure, pulse wave velocity, arterial stiffness index, malondialdehyde and total antioxidant status were assessed at baseline and after 8 weeks of cholecalciferol. The results were analysed using paired ' $t$ ' test.

Results: A total of 119 hypertensive patients were screened for vitamin D status. Among them 57 patients were found to be vitamin D deficient (48.7\%). Thirty two patients completed the study. The baseline serum $25 \mathrm{OH}$ vitamin D3 was $12.55 \pm 5.7 \mathrm{ng} / \mathrm{mL}$ and it increased to $40.06 \pm 10.53 \mathrm{ng} / \mathrm{mL}$ after 8 weeks. Conclusions: The vascular parameters didn't show any statistically significant difference between baseline and at 8 weeks. However trend for decline was observed for malondialdehyde, right brachial pulse wave velocity.
\end{abstract}

Keywords: Arterial stiffness, Cholecalciferol, Hypertension, Malondialdehyde

\section{INTRODUCTION}

Vitamin D referred as sunshine vitamin has recently received much attention due to identification of its effects apart from its actions on bone. The global scenario of pandemic of vitamin D deficiency is associated with many chronic diseases such as cardiovascular diseases and cancers. ${ }^{1}$ The occurrence of higher risk of chronic diseases namely cancers, autoimmune diseases, infectious diseases, and cardiovascular disease with higher latitudes 
is also been attributed to concurrent vitamin D deficiency at these places. ${ }^{2}$ In India, vitamin D deficiency occurs commonly in the range of $70-90 \%$ in all age groups and in either gender. ${ }^{3,4}$ Decreased exposure to sunlight, and lack of vitamin D fortified food intake are some of the reasons put forward for vitamin D deficiency in India. Further it is also postulated that Indians are more prone to cardiovascular diseases because of vitamin D deficiency. ${ }^{5,6}$

Thus studies linking vitamin D deficiency and cardiovascular diseases are of importance in Indian context. Vascular stiffness and inflammation is well regarded as the markers of atherosclerosis. It is also hypothesized that vitamin $\mathrm{D}$ reduces the vascular inflammation and oxidative stress. Recently a study reported association of vitamin $D$ deficiency with inflammation-linked vascular endothelial dysfunction., ${ }^{7,8}$ Replacement of vitamin D has been shown to improve endothelial function. ${ }^{9-11}$ Another study demonstrated that Vitamin D improves carotid femoral pulse wave velocity in Black youths in United States. ${ }^{12}$ Nevertheless, there is a need for prospective Indian studies to investigate causal effect of vitamin D deficiency on vascular endothelial function. Hence the present study was designed to study the effect of vitamin D on vascular health in hypertensive patients with vitamin $\mathrm{D}$ deficiency.

The objective of the study was to assess the effect of vitamin D supplementation on markers of vascular health in hypertensive patients with vitamin D deficiency.

\section{METHODS}

The study was approved by the Institute Ethics Committee, JIPMER, Puducherry, India. The hypertensive patients were recruited from outpatient Departments of Medicine and Endocrinology. Noninvasive vascular parameters were assessed in cardiovascular laboratory of Clinical Pharmacology Department. The study was carried out from February 2013 to April 2014. Written informed consent was obtained before screening. During screening $3 \mathrm{ml}$ of fasting blood sample was drawn from each participant for measuring serum parameters of $25 \mathrm{OH}$ Vitamin D and other biochemical parameters namely malondialdehyde, total antioxidant status, total calcium, phosphorus, glucose, urea, creatinine, total bilirubin, direct bilirubin, aspartate aminotransferase, alkaline phosphatase, alanine transferase. Patients were defined as vitamin D deficient when their serum $25 \mathrm{OH}$ vitamin D3 levels were less than $20 \mathrm{ng} / \mathrm{mL}$.

Inclusion criteria involved subjects known hypertensives on treatment, either gender, aged 30 to 65 years with vitamin D deficiency, serum $25 \mathrm{OH}$ vitamin D3 less than $20 \mathrm{ng} / \mathrm{mL}$. Subjects taking any medications known to affect the calcium or vitamin D metabolism such as corticosteroids, anti-epileptics, hormones; coronary artery disease, peripheral vascular disease, malignancy, sarcoidosis, thyroid diseases, hepatic impairment, renal impairment, pregnant and lactating women were excluded.

After screening subjects were asked to rest in supine position on a couch for ten minutes. Participants were advised not to smoke, or consume food or caffeinated beverages 12 hours prior to each study visit. The noninvasive periscope device was used to measure pulse wave velocity (PWV), arterial stiffness index (ASI) and pulse pressure. Two recordings were taken by applying pneumatic cuffs around the four limbs and electrocardiograph (ECG) electrodes were placed on the chest. Sachets of cholecalciferol (Hexagon Group Co, Nasik, Mfg Lic No. N/N/L/955), 60000 IU/week given for 4 weeks. The patients were asked to take cholecalciferol every week and adherence sheet was given to fill the sheet to ensure compliance with medication. Further, the participants were asked to bring back empty sachets after taking cholecalciferol.

At week 4, $2 \mathrm{ml}$ of blood was collected from each patient for estimating serum calcium and phosphorus and remaining 4 sachets of cholecalciferol were given. History of any change in their drug intake and compliance with cholecalciferol were asked. At week 8, empty sachets were collected and parameters of pulse pressure, pulse wave velocity, arterial stiffness index were measured using "Periscope". Another, $3 \mathrm{ml}$ of blood was collected for serum $25 \mathrm{OH}$ vitamin $\mathrm{D}$, calcium, phosphorous, malondialdehyde and total antioxidant status measurement. History of any change in their drug intake and compliance with cholecalciferol were asked.

\section{Estimation of $25 \mathrm{OH}$ vitamin $\mathrm{D} 3$}

Serum $25 \mathrm{OH}$ vitamin D3 was estimated using LCMS/MS based on method previously described. ${ }^{13}$ Deuterated internal standard of $25 \mathrm{OH}$ vitamin D (d6 25 $\mathrm{OH}$ D) was procured from Avivagen Inc. Canada (previously Chemaphor Inc.). Pure form of $25 \mathrm{OH}$ vitamin D3 was procured from Calidad Industries Mumbai.

\section{Parameters measured}

Pulse wave velocity (PWV) and Arterial stiffness index (ASI) are well regarded as an index of central arterial stiffness. ${ }^{14}$ Periscope a 8 -channel real-time, simultaneous acquisition and analysis PC system, was used to measure pulse wave velocity, arterial stiffness index based principle of oscillometry. ${ }^{15}$ Malondialdehyde (MDA) was estimated by thiobarbituric acid (TBA) test. ${ }^{16}$ Total antioxidant status was estimated by Ferric Reducing Antioxidant Power Assay. ${ }^{17}$

The other biochemical parameters such as total calcium, phosphorus, glucose, urea, creatinine, total bilirubin, direct bilirubin, aspartate aminotransferase, alkaline phosphatase, alanine transferase were measured at 
clinical biochemistry laboratory using Clinical chemistry auto analyzer, Olympus AU 400.

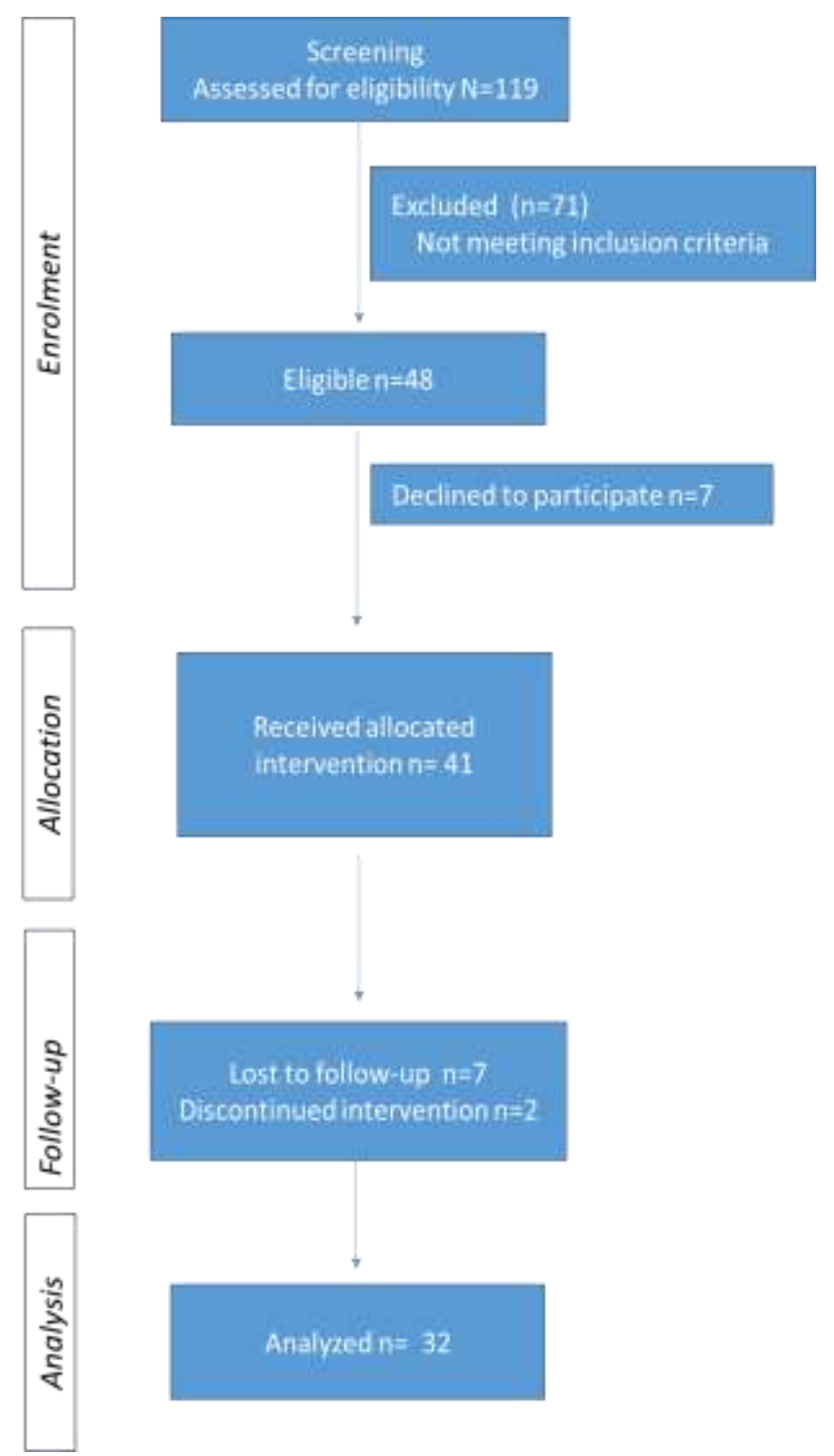

Figure 1: Patient flow chart of the study.

\section{Methods of statistical analysis}

Paired " $t$ " test was used for analysing SBP, DBP, pulse pressure, pulse wave velocity, arterial stiffness index, malondialdehyde (MDA) and total antioxidant status (TAS) before and after the treatment. The values are expressed as mean $\pm \mathrm{SD}$ and $\mathrm{P}$ value $<0.05$ was considered as statistically significant. The analysis was done by GraphPad InStat version 3.

\section{RESULTS}

A total of 119 hypertensive patients were screened for eligibility criteria. Among them 57 patients were found to be vitamin D deficient (48.7\%). Among 57 vitamin D deficient hypertensive patients, 7 were known cases of hypothyroidism and 1 case each of coronary artery disease and migraine. Hence they were excluded and 48 patients were found eligible for the study. Incidentally among total of 9 hypothyroid hypertensive patients screened, 7 were also vitamin $\mathrm{D}$ deficient and only 2 were having normal vitamin D levels.

Table 1: Effect of vitamin D (60000 IU/week for 8 weeks) on patient characteristics $(\mathrm{N}=32)$.

\begin{tabular}{|c|c|c|c|}
\hline Parameters & Baseline & $\begin{array}{l}\text { After } 8 \\
\text { weeks }\end{array}$ & $\begin{array}{l}\mathbf{P} \\
\text { value }\end{array}$ \\
\hline $\begin{array}{l}25 \text { OH D } \\
(\mathrm{ng} / \mathrm{mL})\end{array}$ & $12.55 \pm 5.7$ & $40.06 \pm 10.53$ & $\begin{array}{l}< \\
0.0001\end{array}$ \\
\hline Weight $(\mathrm{Kg})$ & $68.93 \pm 13.65$ & $69.43 \pm 13.46$ & 0.10 \\
\hline BMI $\mathrm{Kg} / \mathrm{m}^{2}$ & $27.42 \pm 5.5$ & $27.62 \pm 5.45$ & 0.09 \\
\hline $\begin{array}{l}\text { HR } \\
\text { (beats/min) }\end{array}$ & $74.31 \pm 8.6$ & $74.00 \pm 8.94$ & 0.80 \\
\hline SBP (mmHg) & $130.53 \pm 11.03$ & $129.03 \pm 10.61$ & 0.41 \\
\hline DBP (mmHg) & $75 \pm 7.25$ & $76.93 \pm 6.88$ & 0.17 \\
\hline $\mathrm{MBP}(\mathrm{mmHg})$ & $93.32 \pm 7.03$ & $94.12 \pm 6.99$ & 0.46 \\
\hline $\mathrm{PP}(\mathrm{mmHg})$ & $55.53 \pm 10.82$ & $52.09 \pm 9.51$ & 0.09 \\
\hline $\begin{array}{l}\text { Right ba PWV } \\
(\mathrm{cms} / \mathrm{s})\end{array}$ & $1746.54 \pm 853.32$ & $\begin{array}{l}1622.96 \pm \\
760\end{array}$ & 0.05 \\
\hline $\begin{array}{l}\text { Left baPWV } \\
(\mathrm{cms} / \mathrm{s})\end{array}$ & $1571.81 \pm 408.46$ & $\begin{array}{l}1490.4 \pm \\
341.09\end{array}$ & 0.16 \\
\hline $\begin{array}{l}\text { cf PWV } \\
(\mathrm{cms} / \mathrm{s})\end{array}$ & $\begin{array}{l}1134.16 \pm \\
462.03\end{array}$ & $\begin{array}{l}1076.00 \pm \\
412.91\end{array}$ & 0.20 \\
\hline $\begin{array}{l}\text { Right bra ASI } \\
(\mathrm{mmHg})\end{array}$ & $27.52 \pm 7.22$ & $26.33 \pm 6.5$ & 0.20 \\
\hline $\begin{array}{l}\text { Left bra ASI } \\
(\mathrm{mmHg})\end{array}$ & $26.46 \pm 7.6$ & $25.33 \pm 7.6$ & 0.28 \\
\hline $\begin{array}{l}\text { Right ank ASI } \\
(\mathrm{mmHg})\end{array}$ & $36.53 \pm 8.2$ & $36.52 \pm 7.18$ & 0.70 \\
\hline $\begin{array}{l}\text { Left ank ASI } \\
(\mathrm{mmHg})\end{array}$ & $35.68 \pm 11.57$ & $36.45 \pm 8.6$ & 0.62 \\
\hline $\begin{array}{l}\text { MDA } \\
(\mu \mathrm{Mol} / \mathrm{L})\end{array}$ & $1.24 \pm 0.66$ & $0.91 \pm 0.60$ & 0.05 \\
\hline TAS $(\mu \mathrm{Mol} / \mathrm{L})$ & $259.98 \pm 216.11$ & $\begin{array}{l}267.50 \pm \\
209.41\end{array}$ & 0.51 \\
\hline
\end{tabular}

Values are in mean $\pm \mathrm{SD}$; HR heart rate, SBP systolic blood pressure, DBP diastolic blood pressure, MBP mean blood pressure, PP pulse pressure, ba PWV brachial aortic pulse wave velocity, cf PWV carotid femoral pulse wave velocity, bra ASI brachial arterial stiffness index, ank ASI ankle arterial stiffness index; MDA malondialdehyde; TAS total antioxidant status; Comparison done by paired " $\mathrm{t}$ " test.

Among 48 eligible patients only 41 accepted to continue in the study and received cholecalciferol 60000 IU/week. Among them 3 patients lost to follow up before $4^{\text {th }}$ week and another 4 patients lost to follow up at $8^{\text {th }}$ week. Two patients (myalgia and head ache) discontinued the medication due to adverse drug reactions (ADRs) before completing 4 weeks and recovered from the symptoms. Adverse drug reactions (ADRs) were noted in total of 4 patients, [2 cases of headache and one case each of increased appetite and myalgia,] and were reported to ADR Monitoring Center (AMC) JIPMER. The ADRs subsided in other two cases without any intervention and both of them completed the study. Thus a total of 32 patients completed the study as shown in the flow chart (Figure 1.) Only one male patient was a smoker with 2-3 cigarettes per day for 25 years. The study participants 
also reported of no change in their regular medications during the study period of 8 weeks. All the study patients were non-vegetarians.

The mean age of patients was 53.09 (minimum of $30 \mathrm{yrs}$ maximum of $53 \mathrm{yrs}$ ). Females constituted 21 and males 11. Mean (SD) of duration of hypertension was 4.48 years (3.5).

The average (SD) of body mass index (BMI) was 27.42 $\mathrm{kg} / \mathrm{m}^{2}$ (5.50). The total calcium, phosphorus, glucose, urea, creatinine, liver function tests were in normal range at baseline.

The serum $25 \mathrm{OH}$ vitamin D3 rised from $12.55 \pm 5.7$ $\mathrm{ng} / \mathrm{mL}$ to $40.06 \pm 10.53 \mathrm{ng} / \mathrm{mL}$ after 8 weeks of cholecalciferol. The vascular parameters were not statistically different as compared to baseline status among study patients. However, the right brachio-ankle pulse wave velocity (right ba PWV) and serum malondialdehyde showed a trend towards decline after 8 weeks of cholecalciferol (Table 1). The serum calcium and phosphorous remained in normal range at $4^{\text {th }}$ week and at $8^{\text {th }}$ week of cholecalciferol.

\section{DISCUSSION}

Vitamin D deficiency in a group of hypertensives $(\mathrm{N}=119)$ was found to be $57(48.7 \%)$. This is in contrast to the previous study by Harinarayan et al, which showed $72.5 \%$ of vitamin D deficiency. ${ }^{3}$ The difference may be attributed to the dietary habits. In our study of 32 patients, there is no difference in BP after vitamin D replacement as compared to baseline. Vitamin D showed a trend for decline in Right ba PWV in our study. The marker of oxidative stress, MDA also has shown trend for decline after vitamin $\mathrm{D}$ indicating reduction in oxidative stress, but these were not statistically significant (Table 1). This might be due to small sample size. The measured parameters of our study namely, pulse wave velocity and arterial stiffness are validated to be used for studying vascular function. ${ }^{18}$

Studies showing improvement in vascular health with vitamin D replacement have demonstrated it with 12 to 16 weeks of therapy. ${ }^{10-12}$ However one study demonstrated improvement of endothelial function as assessed by flow mediated dilation (FMD) with single dose of 100000 IU vitamin D2 at 8 weeks. ${ }^{9}$ Similar to studies done in Africa Americans another study demonstrated reduction in SBP in African American subjects including hypertensives where cholecalciferol was given for 3 months. ${ }^{11,12,19}$ The cholecalciferol 3000 IU/d for 20 weeks also showed significant fall in both SBP and DBP in hypertensives with no effect on carotid femoral PWV. ${ }^{20}$

Similarly, in a recent study a statistically significant reduction in BP after 12 weeks of weekly 50000 IU vitamin $\mathrm{D}$ in type 2 diabetes patients was demonstrated. ${ }^{21}$
Thus duration of therapy also may play role in influencing vascular parameters. The dose of cholecalciferol of $60,000 \mathrm{IU}(1500 \mu \mathrm{g})$ once a week for 8 weeks which is used in our study is commonly used regimen to normalise the vitamin $\mathrm{D}$ levels in overt or occult vitamin D deficiency. ${ }^{22}$

However, there are many negative studies demonstrating lack of effect of vitamin D on vascular health. Vitamin D2 (1,00,000 units) showed improvement in endothelial function as measured by flow mediated dilatation (FMD) at 8 weeks but the effect did not sustain at 16 weeks. ${ }^{23}$ Another study showed lack of effect of cholecalciferol $1,00,000$ IU every 3 months for 1 years on office BP, 24hrs BP and arterial stiffness in elderly patients with isolated systolic hypertension. ${ }^{24}$

Similarly vitamin D showed no effect on BP, endothelial function and other markers of vascular function at 6 months in patients with past history of MI. ${ }^{25}$ The metaanalysis of randomized clinical trials, exploring causal relationship between vitamin D and both SBP and DBP also showed a non-significant reduction in both SBP and DBP with significant evidence of heterogeneity and publication bias among trials of SBP. ${ }^{26}$

Thus effect of vitamin D on vascular markers may depend on various factors such as duration of therapy, method used for assessing endothelial function, race and sample size.

Our study found incidentally the probable association of hypothyroidism with vitamin $\mathrm{D}$ deficiency. This needs to be explored further as vitamin $\mathrm{D}$ receptor belongs to the steroid-receptor gene family and its size and sequence is very close to the thyroid hormone receptor. ${ }^{27}$

The main limitation of our study is small sample size. This was because of lower occurrence of vitamin D deficiency than predicted and stringent eligibility criteria. Further, single arm paired design has the advantage of reducing inter-individual variations, as it compares postintervention data of each subject with baseline values. However, this design is also not well equipped to identify the natural changes over time course in disease as no concurrent comparator is used.

\section{CONCLUSION}

The vascular parameters showed no statistically difference before and after 8 weeks of cholecalciferol. However, there was a trend for decline in malondialdehyde and right brachial pulse wave velocity.

\section{ACKNOWLEDGEMENT}

We thank JIMPER for sanction of intramural research grant under which the study was conducted. 
Funding: No funding sources

Conflict of interest: None declared

Ethical approval: The study was approved by the Institutional Ethics Committee

\section{REFERENCES}

1. Wacker M, Holick MF. Sunlight and Vitamin D: A global perspective for health. Dermatoendocrinol. 2013;5:51-108.

2. Holick MF, Chen TC, Lu Z, Sauter E. Vitamin D and skin physiology: a D-lightful story. J Bone Miner Res. 2007;22:V28-33.

3. Harinarayan CV, Joshi SR. Vitamin D status in IndiaIts implications and Remedial Measures. J Assoc Physicians India. 2009;57:40-8.

4. Marwaha RK, Sripathy G. Vitamin D and Bone mineral density of healthy school children in northern India. Indian J Med Res. 2008;127:239-44.

5. Misra A, Vikram NK. Insulin resistance syndrome (metabolic syndrome) and obesity in Asian Indians: evidence and implications. Nutrition. 2004;20:48291.

6. McCarty MF. Poor vitamin D status may contribute to high risk for insulin resistance, obesity, and cardiovascular disease in Asian Indians. Med Hypotheses. 2009;72:647-51.

7. Jablonski KL, Chonchol M, Pierce GL, Walker AE, Seals DR. 25 Hydroxyvitamin D deficiency is associated with inflammation-linked vascular endothelial dysfunction in middle-aged and older adults. Hypertension. 2011;57:63-9.

8. Syal SK, Kapoor A, Bhatia E, Sinha A, Kumar S, Tewari $\mathrm{S}$ et al. Vitamin D deficiency, coronary artery disease, and endothelial dysfunction: observations from a coronary angiographic study in Indian patients. J Invasive Cardiol. 2012;24:385-9.

9. Sugden JA, Davies JL, Witham MD, Morris AD, Struthers AD. Vitamin D improves endothelial function in patients with type 2 diabetes mellitus and low vitamin D levels. Diabet Med. 2008;25:320-5.

10. Tarcin O, Yavuz DG, Ozben B, Telli A, Ogunc AV, Yuksel $\mathrm{M}$ et al. Effect of vitamin D deficiency and replacement on endothelial function in asymptomatic subjects. J Clin Endocrinol Metab. 2009;94:4023-30.

11. Harris RA, Pedersen-White J, Guo DH, StallmannJorgensen IS, Keeton D, Huang Y et al. Vitamin D3 supplementation for 16 weeks improves flowmediated dilation in overweight African-American adults. Am J Hypertens. 2011;24:557-62.

12. Dong Y, Stallmann-Jorgensen IS, Pollock NK, Harris RA, Keeton D, Huang Y et al. 16-week randomized clinical trial of 2000 international units daily vitamin D3 supplementation in black youth: 25hydroxyvitamin D, adiposity, and arterial stiffness. J Clin Endocrinol Metab. 2010;95:4584-91.

13. van den Ouweland JM, Beijers AM, Demacker PN, van Daal $\mathrm{H}$. Measurement of 25-OH-vitamin D in human serum using liquid chromatography tandemmass spectrometry with comparison to radioimmunoassay and automated immunoassay. J Chromatogr B Analyt Technol Biomed Life Sci. 2010;878:1163-8.

14. Tsuchikura S, Shoji T, Kimoto E, Shinohara K, Hatsuda S, Koyama $\mathrm{H}$ et al. Brachial-ankle pulse wave velocity as an index of central arterial stiffness. J Atheroscler Thromb 2010; 17:658-65.

15. Naidu MU, Reddy BM, Yashmaina S, Patnaik AN, Rani PU. Validity and reproducibility of arterial pulse wave velocity measurement using new device with oscillometric technique: a pilot study. Biomed Eng Online. 2005;4:49.

16. Satoh K. Serum lipid peroxide in cerebrovascular disorders, determined by a new colorimetric method. Clin Chem Acta. 1978;90: 37-43.

17. Benzie IF, Strain JJ. The ferric reducing ability of plasma (FRAP) as a measure of "antioxidant power": the FRAP assay. Anal Biochem. 1996;239:70-6

18. Jadhav UM, Kadam NN. Non-invasive assessment of arterial stiffness by pulse-wave velocity correlates with endothelial dysfunction. Indian Heart J. 2005;57:226-32.

19. Forman JP, Scott JB, Ng K, Drake BF, Suarez EG, Hayden DL, et al. Effect of vitamin D supplementation on blood pressure in blacks. Hypertension. 2013;61:779-85.

20. Larsen T, Mose FH, Bech JN, Hansen AB, Pedersen EB. Effect of cholecalciferol supplementation during winter months in patients with hypertension: a randomized, placebo-controlled trial. Am J Hypertens. 2012;25:1215-22.

21. Nasri H, Behradmanesh S, Ahmadi A, RafieianKopaei M. Impact of oral vitamin D (cholecalciferol) replacement therapy on blood pressure in type 2 diabetes patients; a randomized, double-blind, placebo controlled clinical trial. J Nephropathol. 2014;3:29-33.

22. Goswami R, Gupta N, Ray D, Singh N, Tomar N. Pattern of 25-hydroxy vitamin D response at short (2 month) and long (1 year) interval after 8 weeks of oral supplementation with cholecalciferol in Asian Indians with chronic hypovitaminosis $\mathrm{D}$. Br J Nutr. 2008;100:526-9.

23. Witham MD, Dove FJ, Sugden JA, Doney AS, Struthers AD. The effect of vitamin D replacement on markers of vascular health in stroke patients - a randomised controlled trial. Nutr Metab Cardiovasc Dis. 2012;22:864-70.

24. Witham MD, Price RJ, Struthers AD, Donnan PT, Messow CM, Ford I, et al. Cholecalciferol treatment to reduce blood pressure in older patients with isolated systolic hypertension: the VitDISH randomized controlled trial. JAMA Intern Med. 2013;173:1672-9.

25. Witham MD, Dove FJ, Khan F, Lang CC, Belch JJ, Struthers AD. Effects of vitamin D supplementation on markers of vascular function after myocardial infarction--a randomised controlled trial. Int $\mathbf{J}$ Cardiol. 2013;167:745-9. 
26. Kunutsor SK, Burgess S, Munroe PB, Khan $\mathrm{H}$. Vitamin $\mathrm{D}$ and high blood pressure: causal association or epiphenomenon? Eur J Epidemiol. 2014;29:1-14.
27. Baker AR, McDonnell DP, Hughes M, Crisp TM, Mangelsdorf DJ, Haussler MR et al. Cloning and expression of full-length cDNA encoding human vitamin D receptor. Proc Natl Acad Sci USA. 1988;85:3294-8.

Cite this article as: Srinivasamurthy SK,

Kamalanathan SK, Kolar VV, Sundaram R, Goud

CR, Chandrasekaran A. Effect of vitamin D on

vascular health in hypertensive patients with vitamin

$\mathrm{D}$ deficiency. Int $\mathrm{J}$ Basic Clin Pharmacol

2016;5:2602-7. 